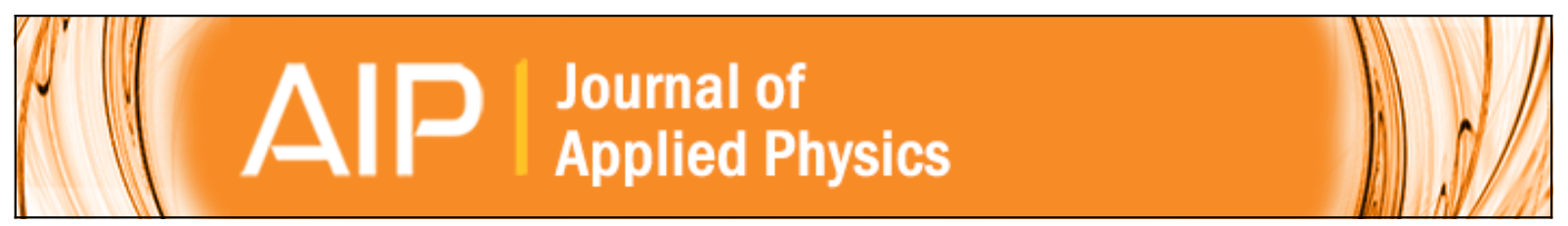

\title{
Perpendicular coercivity enhancement of CoPt/TiN films by nitrogen incorporation during deposition
}

Hongyu An, Jian Wang, Janos Szivos, Takashi Harumoto, Takumi Sannomiya, Shinji Muraishi, Gyorgy Safran,

Yoshio Nakamura, and Ji Shi

Citation: Journal of Applied Physics 118, 203907 (2015); doi: 10.1063/1.4936365

View online: http://dx.doi.org/10.1063/1.4936365

View Table of Contents: http://scitation.aip.org/content/aip/journal/jap/118/20?ver=pdfcov

Published by the AIP Publishing

\section{Articles you may be interested in}

Highly (001) oriented L10-CoPt/TiN multilayer films on glass substrates with perpendicular magnetic anisotropy J. Vac. Sci. Technol. A 33, 021512 (2015); 10.1116/1.4905847

Study on the occurrence of spontaneously established perpendicular exchange bias in Co49Pt51/IrMn bilayers J. Appl. Phys. 115, 17D726 (2014); 10.1063/1.4868915

Microstructure investigations of hcp phase CoPt thin films with high coercivity

J. Appl. Phys. 115, 083910 (2014); 10.1063/1.4866817

Enhancement of perpendicular coercivity for CoPt top layer in CoPt/AIN multilayer structure J. Appl. Phys. 108, 023912 (2010); 10.1063/1.3462428

High coercivity CoPtCr, CoPt films deposited at high power and high bias conditions for hard bias applications in magnetoresistive heads

J. Appl. Phys. 81, 4894 (1997); 10.1063/1.364870

The new SR865 2 MHz Lock-In Amplifier ... \$7950

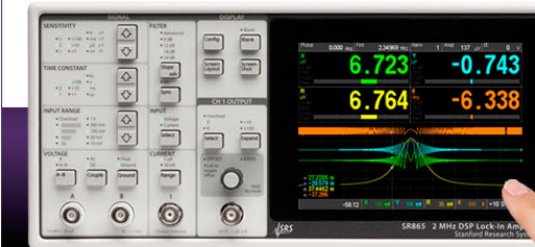

SRS Stanford Research Systems

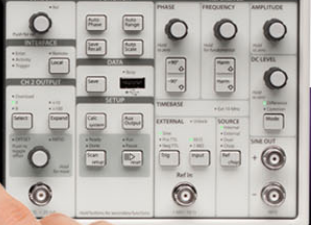

(๑)
Intuitive front-panel operation

Touchscreen data display

Save data \& screen shots to USB flash drive

- Embedded web server and iOS app

Synch multiple SR865s via $10 \mathrm{MHz}$ timebase I/O

View results on a TV or monitor (HDMl output)

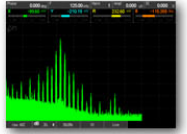

FFT displays

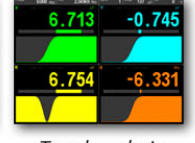

Trend analysis

$1 \mathrm{mHz}$ to $2 \mathrm{MHz}$

$2.5 \mathrm{nV} / \sqrt{ } \mathrm{Hz}$ input noise

$1 \mu$ s to 30 ks time constants

$1.25 \mathrm{MHz}$ data streaming rate

Sine out with DC offset

GPIB, RS-232, Ethernet \& USB 


\title{
Perpendicular coercivity enhancement of CoPt/TiN films by nitrogen incorporation during deposition
}

\author{
Hongyu An, ${ }^{1}$ Jian Wang, ${ }^{2}$ Janos Szivos, ${ }^{3}$ Takashi Harumoto, ${ }^{1}$ Takumi Sannomiya, ${ }^{1}$ \\ Shinji Muraishi, ${ }^{1}$ Gyorgy Safran, ${ }^{3}$ Yoshio Nakamura, ${ }^{1}$ and Ji Shi ${ }^{1, a)}$ \\ ${ }^{1}$ Department of Metallurgy and Ceramics Science, Tokyo Institute of Technology, 2-12-1, Ookayama, \\ Meguro-ku, Tokyo 152-8552, Japan \\ ${ }^{2}$ National Institute for Materials Science (NIMS), Sengen 1-2-1, Tsukuba, Ibaraki 305-0047, Japan \\ ${ }^{3}$ Hungarian Academy of Sciences, Research Institute for Technical Physics and Materials Science, \\ H-1121 Budapest, Konkoly-Thege ut 29-33, Hungary
}

(Received 5 August 2015; accepted 29 October 2015; published online 25 November 2015)

\begin{abstract}
The effect of $\mathrm{N}$ incorporation on the structure and magnetic properties of CoPt thin films deposited on glass substrates with TiN seed layers has been investigated. During the deposition of CoPt, introducing $20 \% \mathrm{~N}_{2}$ into Ar atmosphere promotes the (001) texture and enhances the perpendicular coercivity of CoPt film compared with the film deposited in pure Ar and post-annealed under the same conditions. From the in situ x-ray diffraction results, it is confirmed that $\mathrm{N}$ incorporation expands the lattice parameter of CoPt, which favors the epitaxial growth of CoPt on TiN. During the post-annealing process, $\mathrm{N}$ releases from CoPt film and promotes the $\mathrm{L} 1_{0}$ ordering transformation of CoPt. (C) 2015 AIP Publishing LLC. [http://dx.doi.org/10.1063/1.4936365]
\end{abstract}

\section{INTRODUCTION}

Bit patterned magnetic recording media (BPMR), where each bit is defined by one dot in the patterned dot arrays, is considered to be a promising ultra high density recording technology for the future. ${ }^{1-4}$ In bit patterned media, in order to maximize the signal-to-noise ratio, ${ }^{5}$ a continuous magnetic film with perpendicular magnetic anisotropy is patterned into an ordered array to record the data. ${ }^{6-9}$ Another effective way to further increase the signal-to-noise ratio is to increase the aspect ratio (the ratio between the height and the diameter) of each dot. Large aspect ratios can lower the demagnetization energy and keep sufficient grain volume to maintain the thermal stability. ${ }^{10}$ In order to increase the aspect ratio, the thickness of the continuous magnetic films needs to be increased initially. However, for $\mathrm{L}_{0} \mathrm{FePt}$ or CoPt thin films deposited on amorphous substrates with seed layers, which are the most promising materials that have a practical fabrication method for fabricating BPMR at low cost, increasing the film thickness will generate large c-axis distribution and promote the formation of in-plane variants. ${ }^{11,12}$ For instance, in Perumal's study of FePt films deposited on oxidized $\mathrm{Si}$ substrates with a $\mathrm{MgO}$ seed layer, by increasing the thickness of FePt from $4 \mathrm{~nm}$ to $10 \mathrm{~nm}$, magnetocrystalline anisotropy decreased from $3.9 \times 10^{7} \mathrm{erg} / \mathrm{cc}$ to $1.8 \times 10^{7} \mathrm{erg} / \mathrm{cc}^{11}{ }^{11}$ Therefore, it is desirable to increase the thickness of the films without sacrificing the magnetocrystalline anisotropy. It has been reported that by depositing FePt films in $\mathrm{Ar}$ and $\mathrm{N}_{2}$ atmosphere, $\mathrm{L} 1_{0}$ phase transformation was promoted and in-plane coercivity was enhanced after annealing due to the rapid release of $\mathrm{N}^{13}$ Another study by You et al. reported that by introducing $\mathrm{N}_{2}$ during deposition, $\mathrm{L} 1_{0}$ ordering degree and in-plane coercivity were enhanced for only the FePt films with Fe-rich composition (i.e.,

${ }^{a)}$ E-mail: Shi.j.aa@m.titech.ac.jp
$\left.\mathrm{Fe}_{56} \mathrm{Pt}_{44}\right) \cdot{ }^{14}$ Although the effect of $\mathrm{N}_{2}$ was not clearly revealed and only in-plane coercivity was increased in both studies, they provided a possible way to promote $\mathrm{L}_{0}$ phase transformation. If the addition of $\mathrm{N}_{2}$ during deposition can enhance the perpendicular coercivity in FePt or CoPt thin films, it will be helpful for fabricating continuous magnetic films applied in BPMR with higher magnetocrystalline anisotropy.

In this work, we investigate the structure and magnetic properties of CoPt thin films with thicknesses of $10 \mathrm{~nm}$ by $\mathrm{N}_{2}$ addition during deposition. We show that $\mathrm{L}_{0}$ ordering transformation and perpendicular coercivity are enhanced with $\mathrm{N}_{2}$ addition. The mechanism of the $\mathrm{N}_{2}$ effect is revealed by conducting in situ $\mathrm{x}$-ray diffraction (XRD) measurement by changing the measuring temperature.

\section{EXPERIMENTAL}

$10 \mathrm{~nm}$ thick CoPt films were deposited on fused quartz substrates with $30 \mathrm{~nm}$ thick TiN seed layers at $400^{\circ} \mathrm{C}$ by dc magnetron sputtering. The base pressure in the chamber before deposition was better than $3.75 \times 10^{-7}$ Torr, and the deposition pressure was $1.5 \times 10^{-3}$ Torr. $\mathrm{Co}_{0.44} \mathrm{Pt}_{0.56}$ (composition confirmed by inductively coupled plasma-optical emission spectrometer) film was deposited from a 2 in. composite Co-Pt target. For TiN deposition, the flow rate ratio between $\mathrm{N}_{2}$ and $\left(\mathrm{N}_{2}+\mathrm{Ar}\right)$ was fixed as $10 \%$. For the subsequent $\mathrm{CoPt}$ deposition, the flow rate ratio was changed by $0 \%$ and $20 \%$, respectively. After deposition, samples were annealed at $700^{\circ} \mathrm{C}$ for $1 \mathrm{~h}$ in vacuum (better than $1.9 \times 10^{-6}$ Torr). The thickness of each layer was controlled by deposition time with a pre-calibrated deposition rate.

Magnetic properties were measured using a vibrating sample magnetometer (Riken Denshi BHV-50 V) with a maximum magnetic field of $15 \mathrm{kOe}$. To investigate the structure of the films, XRD profiles were taken using a Bruker D8 Discover diffractometer by applying $\mathrm{Cu} \mathrm{K} \alpha$ radiation. 
Atomic force microscope (AFM) and transmission electron microscopy (TEM) were utilized to observe the surface morphology of the films. Element distribution in the depth direction was measured by time of flight secondary ion mass spectrometry (TOF-SIMS: 5-100-AD).

\section{RESULTS AND DISCUSSION}

Figure 1 shows the surface AFM images of the samples with different $\mathrm{N}_{2}$ flow rate ratios during the deposition of $\mathrm{CoPt}\left(\mathrm{N}_{2}\right.$ flow rate ratio was fixed at $10 \%$ for TiN deposition). CoPt layers exhibit continuous morphology in all samples. The films deposited with $20 \% \mathrm{~N}_{2}$ show larger surface roughnesses compared to those deposited without $\mathrm{N}_{2}$. In Fig. 1(d), after annealing at $700^{\circ} \mathrm{C}$, island-like shapes with brighter contrast appear on the surface of $\mathrm{CoPt}$ layer, which may be due to the surface diffusion of the CoPt layer after annealing at high temperature. However, no such phenomenon occurred in Fig. 1(b), implying that during the annealing process, $\mathrm{N}$ may release from the CoPt layer and promote the surface diffusion of the CoPt layer. The effect of $\mathrm{N}$ will be investigated later by using TOF-SIMS and in situ XRD.

To further investigate the structure of CoPt film, TEM images of the sample with $20 \% \mathrm{~N}_{2}$ annealed at $700^{\circ} \mathrm{C}$ were taken as shown in Fig. 2. As shown in Fig. 2(a), a sharp transition interface can be clearly identified between the $\mathrm{CoPt}$ and TiN layers. The thickness of the TiN layer was estimated and the CoPt layer remains continuous even after annealing at $700^{\circ} \mathrm{C}$. From the HR-TEM image in Fig. 2(b), one can see that due to the annealing effect, larger grains with in-plane grain size of $\sim 20 \mathrm{~nm}$ are formed. The FFT result (the inset of Fig. 2(b)) shows that the CoPt layer is (001) oriented in the perpendicular direction and the (001) reflection can be seen clearly, indicating the formation of $\mathrm{L} 1_{0}$ phase. The
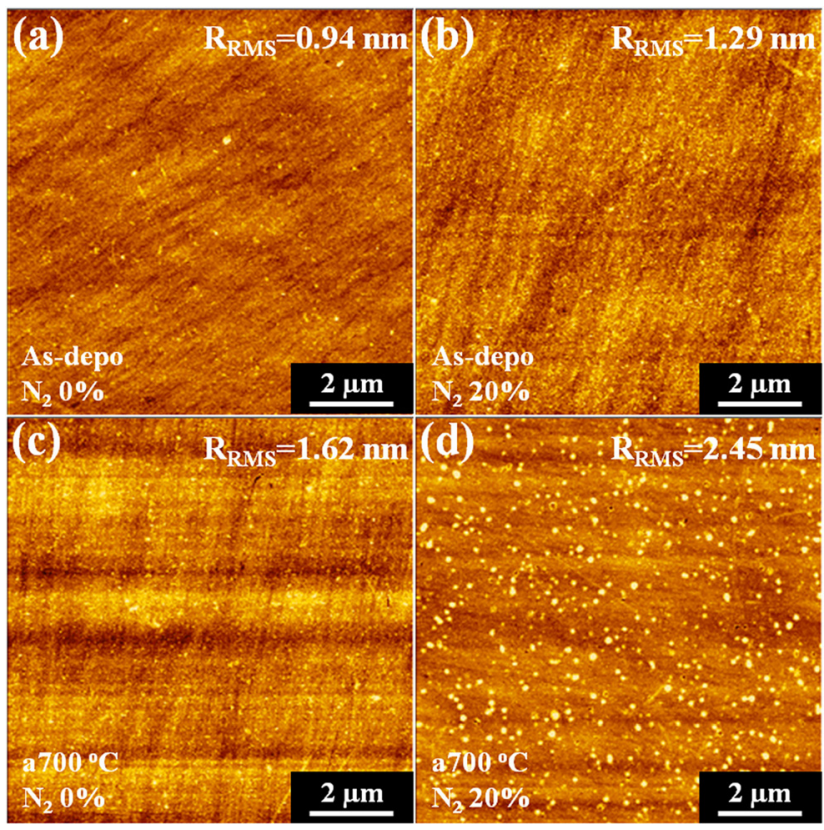

FIG. 1. AFM images of $\operatorname{TiN}(30 \mathrm{~nm}) / \mathrm{CoPt}(10 \mathrm{~nm})$ films with different $\mathrm{N}_{2}$ flow rate ratios during the deposition of CoPt: (a) $0 \%$, before annealing; (b) $20 \%$, before annealing; (c) $0 \%$, annealed at $700{ }^{\circ} \mathrm{C}$; and (d) $20 \%$, annealed at $700^{\circ} \mathrm{C}$.
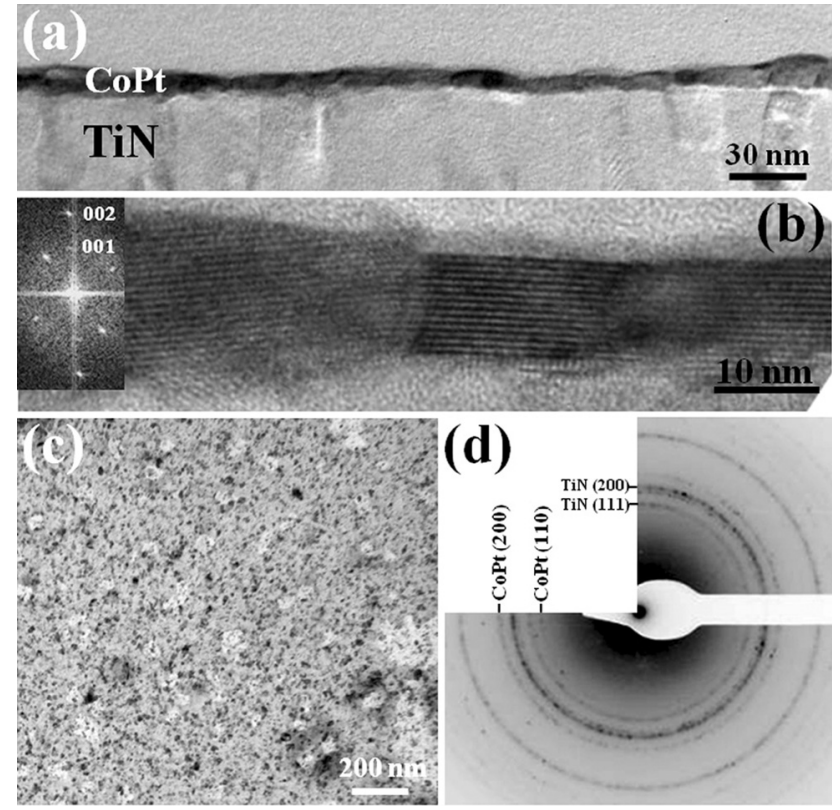

FIG. 2. TEM images of TiN/CoPt films with $\mathrm{N}_{2}$ addition after annealing at $700{ }^{\circ} \mathrm{C}$ : (a) cross-sectional TEM image, (b) HR-TEM image, the inset is the FFT result of CoPt, (c) plan-view TEM image, and (d) electron diffraction pattern.

plan-view TEM in Fig. 2(c) shows that the CoPt layer has polycrystalline structure in the in-plane direction with no preferred orientation. Consistent with the FFT result, a (110) CoPt electron diffraction pattern can be observed in Fig. 2(d), indicating that (001) oriented $\mathrm{L} 1_{0} \mathrm{CoPt}$ structure was formed after annealing at $700^{\circ} \mathrm{C}$.

The corresponding XRD profiles are shown in Fig. 3. Before annealing, the film with $20 \% \mathrm{~N}_{2}$ flow rate ratio exhibits an obviously stronger $\mathrm{CoPt}(200)$ peak than the film with $0 \% \mathrm{~N}_{2}$ flow rate ratio (Fig. 3(a)). As shown in Fig. 3(c), after
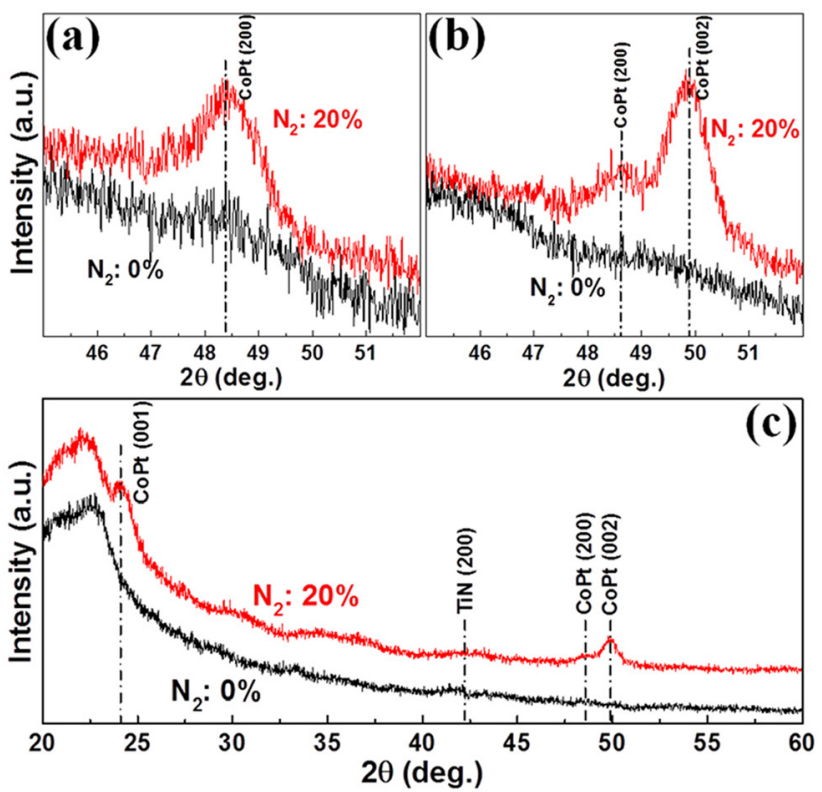

FIG. 3. XRD profiles of $\mathrm{TiN}(30 \mathrm{~nm}) / \mathrm{CoPt}(10 \mathrm{~nm})$ films with different $\mathrm{N}_{2}$ flow rate ratios during the deposition of CoPt: (a) before annealing, (b) after annealing at $700^{\circ} \mathrm{C}$, and (c) XRD profiles with a larger range for the samples after annealing at $700^{\circ} \mathrm{C}$. 
annealing at $700{ }^{\circ} \mathrm{C}$, the film with $20 \% \mathrm{~N}_{2}$ flow rate ratio shows stronger $\mathrm{CoPt}(001)$ and (002) peaks compared with the film deposited with $0 \% \mathrm{~N}_{2}$ flow rate ratio (comparisons of the enlarged (002) peak are shown in Fig. 3(b)). The $\mathrm{L} 1_{0}$ ordering parameter is calculated to be about 0.73 for the film with $\mathrm{N}_{2}$ deposition after annealing at $700{ }^{\circ} \mathrm{C} .{ }^{15}$ While for the film deposited without $\mathrm{N}_{2}$, no obvious (001) CoPt peak is detected after annealing, which makes it difficult to calculate the $\mathrm{L1}_{0}$ ordering parameter. The above phenomenon indicates that introducing $\mathrm{N}_{2}$ during the deposition of $\mathrm{CoPt}$ promotes the (100) orientation of the CoPt layer, which also promotes the $\mathrm{L} 1_{0}$ ordering transformation of $\mathrm{CoPt}$ after annealing.

Figure 4 shows the corresponding $M-H$ curves of $\operatorname{TiN}(30 \mathrm{~nm}) / \mathrm{CoPt}(10 \mathrm{~nm})$ films after annealing at $700^{\circ} \mathrm{C}$. Without introducing $\mathrm{N}_{2}$ during the deposition of $\mathrm{CoPt}$, the sample shows similar magnetization behavior in the in-plane and perpendicular directions with a perpendicular coercivity of $3.7 \mathrm{kOe}$. By introducing $20 \% \mathrm{~N}_{2}$, perpendicular magnetic anisotropy is obtained and the perpendicular coercivity increases to $9.5 \mathrm{kOe}$. The perpendicular coercivity enhancement with $\mathrm{N}_{2}$ addition during the deposition of CoPt is consistent with the XRD results and further confirms that $\mathrm{N}_{2}$ addition can promote the $\mathrm{L}_{0}$ ordering transformation of CoPt.

The above study shows that by introducing $\mathrm{N}_{2}$ into $\mathrm{Ar}$ atmosphere during the deposition of $\mathrm{CoPt}, \mathrm{CoPt}$ (100) preferred orientation is promoted, and after annealing, $\mathrm{L} 1_{0}$ ordering transformation is also promoted, leading to an enhancement of perpendicular magnetic anisotropy. However, the mechanism of the $\mathrm{N}_{2}$ effect is still not clear. One possible mechanism is that during the annealing process, $\mathrm{N}$ atoms release from the CoPt layer, which promotes the diffusion mobility of $\mathrm{Co}$ and $\mathrm{Pt}$ atoms, favoring the $\mathrm{L} 1_{0}$ ordering transformation of CoPt. In order to understand how the $\mathrm{N}$ incorporation affects the structure and magnetic properties of $\mathrm{CoPt}$ films, we focused on $\mathrm{N}$ content changes in the $\mathrm{CoPt}$ layer before and after annealing. As shown in the elemental depth profiles in Fig. 5, before annealing, $\mathrm{N}$-involving components show high intensities within the CoPt layer, as denoted by $\mathrm{CoN}^{-}, \mathrm{PtN}^{-}$, and $\mathrm{CoPtN}^{-}$. However, after annealing, $\mathrm{N}$-involving components drastically decreased (highlighted by red squares). Obvious changes cannot be observed for other elements before and after annealing. This phenomenon indicates that $\mathrm{N}$ effused out from the CoPt layer after the postannealing process.

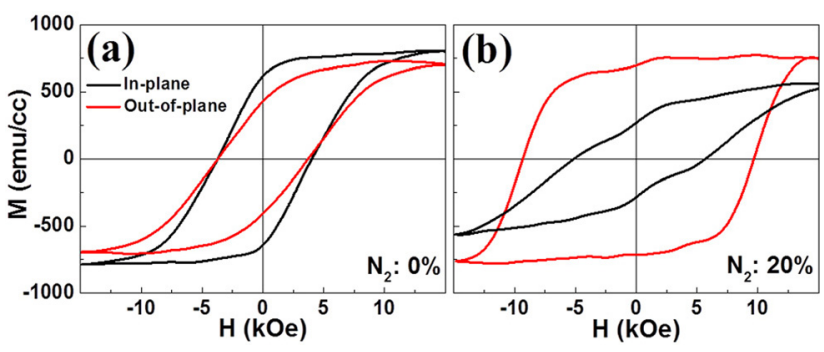

FIG. 4. $M-H$ curves of $\mathrm{TiN}(30 \mathrm{~nm}) / \mathrm{CoPt}(10 \mathrm{~nm})$ films with different $\mathrm{N}_{2}$ flow rate ratio during the deposition of CoPt: (a) $0 \%$ and (b) $20 \%$. Both samples were annealed at $700^{\circ} \mathrm{C}$.

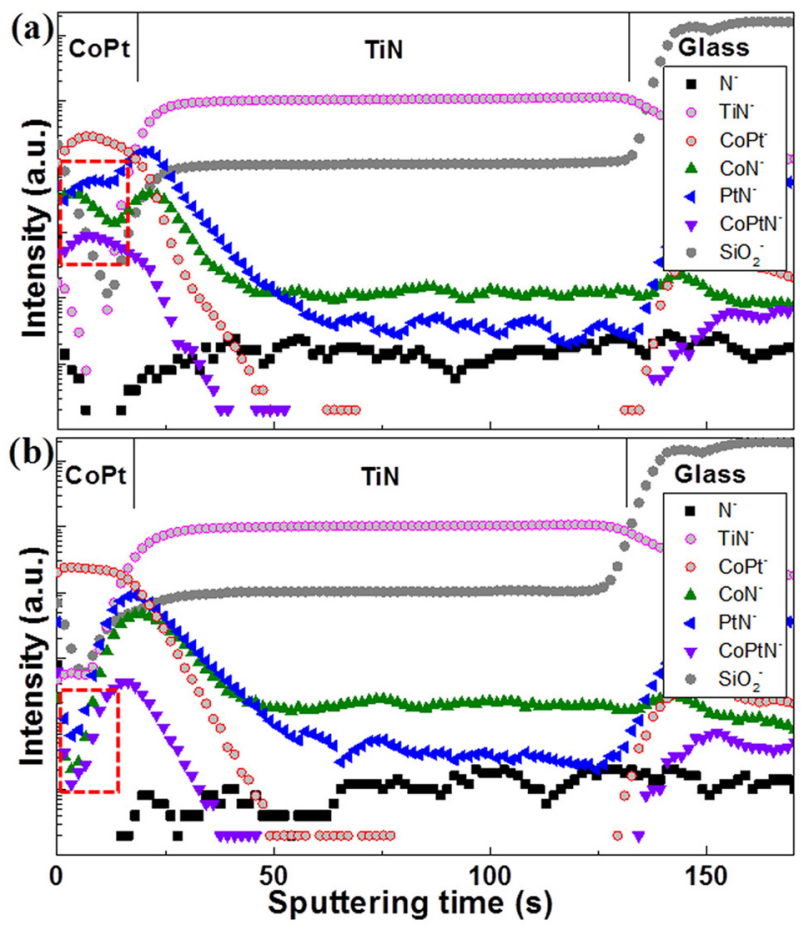

FIG. 5. TOF-SIMS depth profiles of $\operatorname{TiN}(30 \mathrm{~nm}) / \mathrm{CoPt}(10 \mathrm{~nm})$ with $\mathrm{N}_{2}$ flow rate ratio of $20 \%$ during the deposition of CoPt: (a) before annealing and (b) after annealing at $700^{\circ} \mathrm{C}$. Red squares indicate $\mathrm{N}$-involving components change before and after annealing.

As is well known, when depositing CoPt on the TiN seed layer, local epitaxial growth between CoPt and $\mathrm{TiN}$ occurs, ${ }^{15}$ and with a mismatch of $10.4 \%$ between $\mathrm{CoPt}$ $(\sim 0.38 \mathrm{~nm})$ and TiN $(\sim 0.424 \mathrm{~nm})$, large in-plane tensile stress will be generated in the CoPt layer. It is considered that during the deposition of $\mathrm{CoPt}$, the incorporated $\mathrm{N}$ in CoPt can increase the lattice parameter of CoPt and benefit the epitaxial growth of $\mathrm{CoPt}$ on TiN. On the other hand, during the annealing process, $\mathrm{N}$ effuses out from the CoPt layer, which can promote the diffusion mobility of Co and Pt atoms leading to the enhancement of $\mathrm{L} 1_{0}$ ordering transformation. To verify the above interpretation, in situ XRD was taken by changing the measuring temperature for the sample deposited with $\mathrm{N}_{2}$. As shown in Fig. 6, the temperature of the sample was increased and then decreased twice to observe the CoPt (200) peak position shift. As indicated by the dashed line in Fig. 6(a), by increasing the temperature up to $500^{\circ} \mathrm{C}$, the peak shifts to a lower angle, which indicates the thermal expansion of the lattice parameter. However, above $500^{\circ} \mathrm{C}$, despite the thermal expansion, the peak begins to shift to a higher angle, indicating the shrinkage of the lattice parameter. Two possible reasons may be responsible for this phenomenon, $\mathrm{L} 1_{0}$ ordering transformation (lattice parameter $c$ is smaller than $a$ in the $\mathrm{L} 1_{0}$ structure) and $\mathrm{N}$ release. However, since the peak starts to shift to a higher angle around $500^{\circ} \mathrm{C}$, which is much lower than the $\mathrm{L} 1_{0}$ ordering transformation temperature (above $600{ }^{\circ} \mathrm{C}$ ), ${ }^{15} \mathrm{~L}_{0}$ ordering transformation can be excluded. Furthermore, by examining the measurements in the temperature decrease of the first cycle and the subsequent increase-decrease of temperatures, the peak only shifts by following the effect of the thermal expansion. 


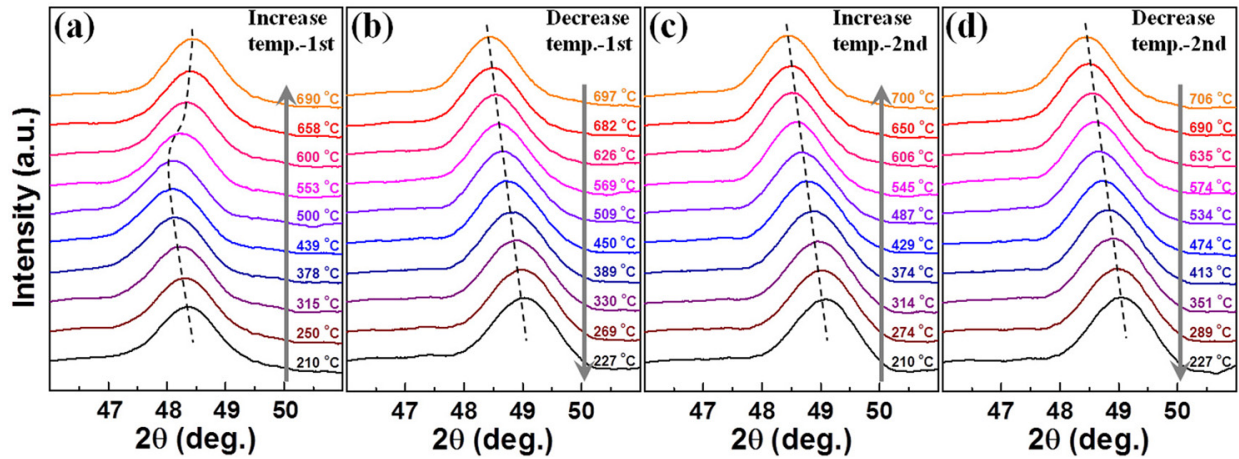

FIG. 6. In situ XRD profiles of $\operatorname{TiN}(30 \mathrm{~nm}) / \mathrm{CoPt}(10 \mathrm{~nm})$ with $\mathrm{N}_{2}$ flow rate ratio of $20 \%$ during the deposition of CoPt: (a) Increasing temperature in the first cycle, (b) decreasing temperature in the first cycle, (c) increasing temperature in the second cycle, and (d) decreasing temperature in the second cycle. The peak is $\mathrm{CoPt}$ (200) peak, and all XRD profiles are smoothed without changing the shapes and the peak positions.
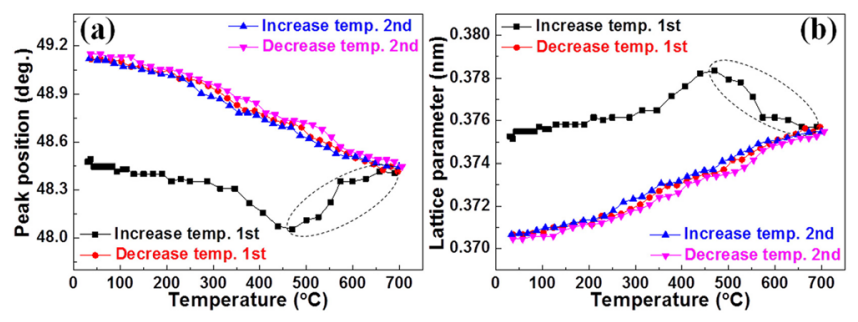

FIG. 7. (a) CoPt (200) peak position dependence on in situ XRD temperatures, (b) CoPt perpendicular lattice parameter dependence on in situ XRD temperatures. Dashed circle indicates the drastic change due to $\mathrm{N}$ release.

Therefore, the peak shift to a higher angle in Fig. 6(a) is caused by $\mathrm{N}$ release.

The dependence of the CoPt (200) peak position and calculated CoPt lattice parameter on measuring temperatures is summarized and plotted in Fig. 7. As shown in Fig. 7(a), the measurement of increasing temperature in the first cycle has a large deviation from the subsequent measurements. This indicates that $\mathrm{N}$ released during the temperature increase process in the first cycle and thermal expansion is responsible for the peak position changes in the subsequent measurements. As shown in Fig. 7(b), the CoPt lattice parameter increases with measuring temperature up to $470{ }^{\circ} \mathrm{C}$ due to thermal expansion. Above $470^{\circ} \mathrm{C}$, the lattice parameter drastically decreases with the further increase of the measuring temperature due to $\mathrm{N}$ release. By comparing the lattice parameter measured at room temperature before $(\sim 0.3753 \mathrm{~nm})$ and after $\mathrm{N}$ release $(\sim 0.3707 \mathrm{~nm})$, it is found that the CoPt lattice parameter is $1.24 \%$ larger in the as-deposited status. The above in situ XRD results are consistent with our interpretation. $\mathrm{N}$ incorporation can expand the lattice parameter of CoPt and benefit the epitaxial growth between CoPt and TiN. Through the post-annealing process, the release of $\mathrm{N}$ can promote the mobility of Co and Pt atoms and favor the $\mathrm{L} 1_{0}$ ordering transformation of CoPt.

\section{CONCLUSIONS}

In conclusion, the effect of $\mathrm{N}$ incorporation on the structure and magnetic properties of $\mathrm{CoPt} / \mathrm{TiN}$ thin films has been studied. Introducing $\mathrm{N}_{2}$ during the deposition of CoPt can promote the crystallinity and $\mathrm{L} 1_{0}$ ordering transformation of CoPt leading to the enhancement of the perpendicular coercivity. It is confirmed that $\mathrm{N}$ incorporation can increase the lattice parameter of $\mathrm{CoPt}$, and promote its epitaxial growth on the TiN seed layer. During the annealing process, release of $\mathrm{N}$ from CoPt film promotes the diffusion mobility of $\mathrm{Co}$ and $\mathrm{Pt}$ atoms, which enhances the $\mathrm{L} 1_{0}$ ordering transformation of CoPt.

\section{ACKNOWLEDGMENTS}

We gratefully acknowledge the Center for Advanced Materials Analysis of Tokyo Institute of Technology for the TOF-SIMS measurements.

${ }^{1}$ R. L. White, R. M. H. New, and R. F. W. Pease, IEEE Trans. Magn. 33, 990 (1997).

${ }^{2}$ H. J. Richter, A. Y. Dobin, O. Heinonen, K. Z. Gao, R. J. M. v. d. Veerdonk, R. T. Lynch, J. Xue, D. Weller, P. Asselin, M. F. Erden, and R. M. Brockie, IEEE Trans. Magn. 42, 2255 (2006).

${ }^{3}$ H. J. Richter, A. Y. Dobin, R. T. Lynch, D. Weller, R. M. Brockie, O. Heinonen, K. Z. Gao, J. Xue, R. J. M. v. d. Veerdonk, P. Asselin, and M. F. Erden, Appl. Phys. Lett. 88, 222512 (2006).

${ }^{4}$ B. D. Terris and T. Thomson, J. Phys. D: Appl. Phys. 38, R199 (2005).

${ }^{5}$ J. C. Mallinson, IEEE Trans. Magn. 27, 3519 (1991).

${ }^{6}$ A. T. McCallum, P. Krone, F. Springer, C. Brombacher, M. Albrecht, E. Dobisz, M. Grobis, D. Weller, and O. Hellwig, Appl. Phys. Lett. 98, 242503 (2011).

${ }^{7}$ T. Shimatsu, Y. Inaba, H. Kataoka, J. Sayama, H. Aoi, S. Okamoto, and O. Kitakami, J. Appl. Phys. 109, 07B726 (2011).

${ }^{8}$ J. W. Liao, K. F. Huang, L. W. Wang, W. C. Tsai, W. C. Wen, C. C. Chiang, H. J. Lin, F. H. Chang, and C. H. Lai, Appl. Phys. Lett. 102, 062420 (2013).

${ }^{9}$ T. Bublat and D. Goll, Nanotechnology 22, 315301 (2011).

${ }^{10}$ K. F. Dong, H. H. Li, Y. G. Peng, G. Ju, G. M. Chow, and J. S. Chen, Appl. Phys. Lett. 104, 192404 (2014).

${ }^{11}$ A. Perumal, Y. K. Takahashi, T. O. Seki, and K. Hono, Appl. Phys. Lett. 92, 132508 (2008).

${ }^{12}$ S. Jeong, Y. N. Hsu, D. E. Laughlin, and M. E. McHenry, IEEE Trans. Magn. 36, 2336 (2000).

${ }^{13}$ H. Y. Wang, W. H. Mao, X. K. Ma, H. Y. Zhang, Y. B. Chen, Y. J. He, and E. Y. Jiang, J. Appl. Phys. 95, 2564 (2004).

${ }^{14}$ C. Y. You, Y. K. Takahashi, and K. Hono, J. Appl. Phys. 98, 013902 (2005).

${ }^{15}$ H. An, J. Wang, T. Sannomiya, S. Muraishi, Y. Nakamura, and J. Shi, J. Phys. D: Appl. Phys. 48, 155001 (2015). 